\title{
RUBISCO ACTIVITY IS ALTERED IN A STARCHLESS MUTANT OF NICOTIANA SYLVESTRIS GROWN IN ELEVATED CARBON DIOXIDE
}

\author{
RIGHARD C. SICHER* and DIANE F. KREMER
}

U.S. Department of Agriculture, Agricultural Research Service, Climate Stress Laboratory, Beltsville Agricultural Research Center-west, 10300 Baltimore Avenue Beltsville MD 20705-2350 USA

(Received 6 February 1996; accepted in rezised form 10 fune 1996)

\begin{abstract}
Dry matter and net photosynthesis of a wild type and a starchless mutant NS 458 of Nicotiana syluestris (Speg. et Comes) were studied after $25 \mathrm{~d}$ of $\mathrm{CO}_{2}$ enrichment. Plants were grown from seed in controlled environment chambers and treatments of either ambient $(35 \mathrm{~Pa})$ or twice ambient $(70 \mathrm{~Pa})$ $\mathrm{CO}_{2}$ were initiated when plants were 3-4 weeks old. Photosynthetic rates measured at 35 and $70 \mathrm{~Pa}$ $\mathrm{CO}_{2}$ and at $900 \mu$ mole quanta $\mathrm{m}^{-2} \mathrm{~s}^{-1}$ were unaffected $(P>0.05)$ by $25 \mathrm{~d}$ of $\mathrm{CO}_{2}$ enrichment. However, a $\mathrm{CO}_{2}$-by-genotype interaction was observed indicating that photosynthetic rates of the wild type but not the mutant at $35 \mathrm{~Pa} \mathrm{CO}_{2}$ differed in response to $\mathrm{CO}_{2}$ enrichment. Photosynthetic enhancement was greater $(P<0.001)$ in the wild type than in the mutant when the measurement $\mathrm{CO}_{2}$ was doubled. Total biomass and leaf areas of the mutant and wild type also were unaffected by $\mathrm{CO}_{2}$ enrichment, although specific leaf weight increased $27 \%$ and $13 \%(P<0.001)$ for the wild type and mutant lines, respectively. Neither chlorophyll nor soluble leaf protein were affected by $\mathrm{CO}_{2}$ enrichment. Starch, sucrose, glucose and fructose in wild type and mutant leaf samples were also unaffected by $\mathrm{CO}_{2}$ enrichment. Rubisco protein levels of the wild type and mutant were about $20 \%$ lower in elevated compared to ambient $\mathrm{CO}_{2}$-grown plants. Initial and total Rubisco activities of wild type and mutant leaf samples were not significantly different $(P>0.05)$ between $\mathrm{CO}_{2}$ environments. However, initial Rubisco activity was more than $30 \%$ lower in mutant than than in wild type samples when results from ambient and elevated $\mathrm{CO}_{2}$-grown plants were combined. Ribulose 1,5bisphosphate and 3-phosphoglycerate were $280 \%$ and $28 \%$ greater in the mutant than in the wild type, respectively. These findings suggested that photosynthesis rates of the mutant were limited by Rubisco activity at $35 \mathrm{~Pa} \mathrm{CO}_{2}$ and that end product synthesis rates limited photosynthesis of the mutant at $70 \mathrm{~Pa} \mathrm{CO}_{2}$.
\end{abstract}

Key words: Photosynthetic acclimation, $\mathrm{CO}_{2}$ enrichment, leaf metabolites, Nicotiana sylvestris, photosynthate partitioning.

\section{INTRODUCTION}

During photosynthesis $\left(\mathbf{P}_{\mathrm{n}}\right)$, rates of $\mathrm{CO}_{2}$ fixation are coordinated with rates of end product synthesis. ${ }^{(1,2)}$ Starch and sucrose are the principal end products of $P_{n}$ in most higher plants. If rates of starch and sucrose synthesis are low relative to $\mathrm{CO}_{2}$ fixation, then rates of $\mathrm{P}_{n}$ will decrease because inorganic phosphate levels in the chloroplast become limiting for ATP synthesis. If rates of starch and sucrose synthesis are in excess then triose phosphate concentrations will be too low to regenerate the sub-

*Tel: (301) 504-6632; FAX: (301) 504-6626. 
strate molecule for $\mathrm{CO}_{2}$ fixation, ribulose 1,5bisphosphate ( $\mathrm{Rul}, 5 \mathrm{bisP})$. The biochemical mechanisms responsible for inhibiting $\mathrm{CO}_{2}$ fixation during end product synthesis limited $\mathrm{P}_{\mathrm{n}}$ are not well understood, though deactivation of the $\mathrm{CO}_{2}$ fixing enzyme, ribulose bisphosphate carboxylase/ oxygenase (Rubisco), and decreased levels of inorganic phosphate in the chloroplast have been implicated. $^{(3-5)}$

Rates of starch and sucrose synthesis usually are sufficient to maintain high rates of $P_{n}$ under typical conditions employed for plant growth. However, an end product synthesis limitation of $P_{n}$ can be induced when starch or sucrose biosynthesis is restricted. ${ }^{(2,6)}$ Several species of plants with genetic lesions in the starch biosynthetic pathway have been described $^{(7-9)}$ The mutant (MUT) lines have reduced or trace amounts of leaf starch, elevated soluble sugars and a $\mathrm{P}_{\mathrm{n}}$ rate comparable to the wild type (WT) at ambient $\mathrm{CO}_{2}$. Rates of $\mathrm{P}_{\mathrm{n}}$ of a starchless tobacco MUT were decreased relative to the WT in response to short-term elevated $\mathrm{CO}_{2}$ treatment. Oscillations of $\mathrm{P}_{\mathrm{n}}$ and chlorophyll a fluorescence also were observed in the MUT but not the WT upon exposure to high light and $\mathrm{CO}_{2} \cdot{ }^{\left({ }^{10}\right)}$ These observations are consistent with an end product synthesis limitation of $P_{n}$, although Rubisco activity has not been examined in the MUT.

A second proposed mechanism of feed back inhibited $P_{n}$ is that excessive starch and sucrose levels repress the expression of certain photosynthetic genes. ${ }^{(2,11)}$ Decreased levels of Rubisco have been observed in long-term elevated $\mathrm{CO}_{2}$ experiments and this was correlated with changes in leaf mRNA levels encoding the Rubisco small subunit and other genes. ${ }^{(12,6,11)}$ The photosynthetic responses of both WT and starchless tobacco MUT NS 458 to $\mathrm{CO}_{2}$ enrichment were examined in the current study. We hypothesized that Rubisco activity in the starchless MUT would be down regulated during growth in elevated $\mathrm{CO}_{2}$ and that the mechanism would involve either an end product synthesis limitation of $\mathrm{P}_{\mathrm{n}}$ or decreased Rubisco protein levels.

\section{MATERIALS AND METHODS}

\section{Plant materials}

Experiments were performed using WT and MUT line NS 458 of Nicotiana sylvestris [Speg. et
Comes]. The MUT produces a defective plastid isoform of phosphoglucomutase and contains almost no leaf starch. ${ }^{(8)}$ Seeds were obtained from Dr. Neil McHale, Department of Biochemistry and Genetics, Connecticut Agricultural Experiment Station, New Haven, CT, and were germinated in controlled environment chambers as described earlier. ${ }^{(13)}$ After $25 \mathrm{~d}$ growth, $8 \mathrm{WT}$ and $8 \mathrm{MUT}$ seedlings were transferred to individual $3 \mathrm{dm}^{3}$ plastic pots filled with equal parts Jiffy Mix (Jiffy Products, Batavia, IL) and vermiculite (WR Grace and Co., Cambridge, MA). Plants were grown for an additional $25 \mathrm{~d}$ at $27^{\circ} \mathrm{C}, 450 \mu \mathrm{mol} \mathrm{m}^{-2} \mathrm{~s}^{-1}$, PPFD, and either ambient $(35 \mathrm{~Pa})$ or twice ambient $(70 \mathrm{~Pa})$ $\mathrm{CO}_{2}$ levels as described previously. ${ }^{(14)}$

\section{Experimental details}

Experiments employed $4 \mathrm{~W}^{\prime} \mathrm{T}$ and $4 \mathrm{MUT}$ plants each per $\mathrm{CO}_{2}$ treatment. Following the first harvest, the elevated and ambient $\mathrm{CO}_{2}$ chambers were reversed and the study was repeated. All measurements were performed $50 \mathrm{~d}$ after planting and data from both experiments were combined for analysis. Significant differences were compared by a twoway analysis of variance procedure (SuperANOVA, Abacus Concepts, Berkeley, CA) and $n=8$, except where indicated. Approximately $2 \mathrm{~h}$ after the start of the light period, the ambient and elevated $\mathrm{CO}_{2}$ grown plants were transferred to matching controlled environment chambers with conditions as for plant growth, except that the irradiance was doubled to $900 \mu \mathrm{mol}$ quanta $\mathrm{m}^{-2} \mathrm{~s}^{-1}$. After a $1 \mathrm{~h}$ acclimation period, $P_{n}$ was measured on the sixth true leaf from emergence at 35 and $70 \mathrm{~Pa} \mathrm{CO}_{2}$, as described previously. ${ }^{(15,13)}$ The initiation of this leaf coincided with the onset of the elevated $\mathrm{CO}_{2}$ treatment. ${ }^{(8)}$ Increasing the PPFD used for measuring $P_{n}$ facilitated measuring photosynthetic acclimation to $\mathrm{CO}_{2} \cdot{ }^{(14)}$ The plants were then returned to the respective chambers used for plant growth, and after an additional $2 \mathrm{~h}$ acclimation period, leaf discs $\left(0.8 \mathrm{~cm}^{2}\right.$ each] were removed from the lamina of the leaf that was used to measure $P_{n}$. In addition, tissue near the leaf tip was sampled with a freeze clamp apparatus to measure photosynthetic intermediates. Shoots were harvested for dry weight and leaf area analysis when sampling was completed. ${ }^{(15)}$ Ribulose 1,5-bisphosphate carboxylase/oxygenase (Rubisco) activity, Rubisco protein, soluble protein and chlorophyll ( $\mathrm{Chl})$ were measured as described 
Table 1. Significant differences were determined by two-way analysis of variance. Values are the probability of obtaining a greater $F$, given equal means. Calculations were based on $n=16$, except an asterisk indicates $n=8$.

\begin{tabular}{|c|c|c|c|}
\hline Parameter & $\mathrm{CO}_{2}$ & genotype & $\begin{array}{c}\mathrm{CO}_{2}{ }^{*} \\
\text { genotype }\end{array}$ \\
\hline Leaf area & 0.1119 & 0.7369 & 0.7575 \\
\hline Shoot dry weight & 0.6237 & 0.0190 & 0.8807 \\
\hline SLW & 0.0004 & 0.0001 & 0.0788 \\
\hline Chl & 0.0585 & 0.1311 & 0.8746 \\
\hline Protein & 0.7018 & 0.8313 & 0.9749 \\
\hline Rubisco protein* & 0.0159 & 0.0466 & 0.9725 \\
\hline $\mathrm{P}_{\mathrm{n}}$ at $35 \mathrm{~Pa} \mathrm{CO}_{2}$ & 0.0729 & 0.0887 & 0.0129 \\
\hline $\mathrm{P}_{\mathrm{n}}$ at $70 \mathrm{~Pa} \mathrm{CO}_{2}$ & 0.2130 & 0.0001 & 0.0826 \\
\hline Initial activity & 0.7122 & 0.0294 & 0.6430 \\
\hline Total activity & 0.3598 & 0.1097 & 0.6791 \\
\hline Starch & 0.3598 & 0.0001 & 0.5326 \\
\hline Sucrose & 0.9460 & 0.7564 & 0.9641 \\
\hline Glucose & 0.0539 & 0.0002 & 0.7220 \\
\hline Fructose & 0.9841 & 0.0025 & 0.8915 \\
\hline Rul, 5bisP & 0.0759 & 0.0001 & 0.0048 \\
\hline 3-PGA & 0.0262 & 0.6914 & 0.9257 \\
\hline
\end{tabular}

elsewhere. ${ }^{(14,13)}$ Carbohydrates and the photosynthetic intermediates, Rul,5bisP and glycerate 3-phosphate (3-PGA), were measured using coupled enzyme assays as described previously. ${ }^{(21,22)}$

\section{RESULTS}

\section{Growth analyses}

Neither leaf area nor total shoot dry weight of WT or MUT plants was significantly different $(P>0.05$; Table 1$)$ when plants were grown at 35 and $70 \mathrm{PaCO} \mathrm{CO}_{2}$ (Fig. 1(A) and $\left.1(\mathrm{~B})\right)$. Averaged over $\mathrm{CO}_{2}$ treatments, total shoot dry weights of the WT and MUT were $10.3 \pm 0.3$ and $8.3 \pm 0.4 \mathrm{~g}$ $(P<0.05)$, respectively. In agreement with earlier findings using $\mathcal{N}$. tabacum, ${ }^{(16,13)}$ specific leaf weight (SLW) of the MUT and WT was greater $(P<0.001)$ at 70 than at $35 \mathrm{~Pa} \mathrm{CO}_{2}$ (Fig. $\left.1(\mathrm{C})\right)$. Neither Chl (Fig. 1(D)) nor pheophytin (data not shown) differed $(P>0.05)$ in either the WT or MUT with respect to $\mathrm{CO}_{2}$ treatment. Soluble protein concentrations in WT and MUT plants did not differ $(P>0.05)$ between $\mathrm{CO}_{2}$ treatments, but Rubisco protein decreased about $20 \%(P<0.05)$ in the WT and MUT when the $\mathrm{CO}_{2}$ concentration was doubled
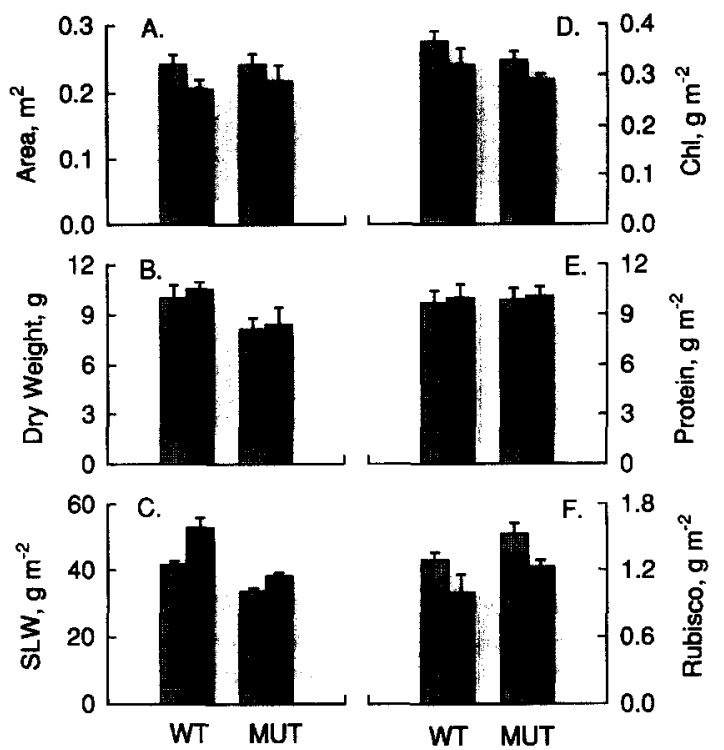

Fig. 1. Effects of $\mathrm{CO}_{2}$ enrichment on total above ground biomass and on various leaf constituents of WT and starchless MUT NS 458 of Nicotiana syluestris. Differences of leaf area (A), shoot dry weight (B), specific leaf weight $(\mathrm{C}), \mathrm{Chl}(\mathrm{D})$, total soluble protein (E) and Rubisco protein (F) are shown for ambient (shaded) and elevated (solid) $\mathrm{CO}_{2}$-grown plants. Vertical bars represent $\pm \mathrm{SE}$ for $n=8$.

from 35 to $70 \mathrm{~Pa}$. Rubisco protein concentrations also were greater in WT than in MUT leaf samples $(P<0.05)$ when averaged over $\mathrm{CO}_{2}$ treatments.

\section{$P_{\mathrm{n}}$ and Rubisco actitity}

The mean rate of $P_{n}$ of the ambient $\mathrm{CO}_{2}$-grown WT was $13.7 \pm 0.4 \mu \mathrm{mol} \mathrm{m}^{-2} \mathrm{~s}^{-1}$, when measured at $35 \mathrm{PaCO}_{2}$ and at a PPFD of $900 \mu \mathrm{mol} \mathrm{m}^{-2} \mathrm{~s}^{-1}$ (Table 2). This $P_{n}$ rate increased $65 \%$ in response to a short-term doubling of the $\mathrm{CO}_{2}$ concentration. The rate of $\mathrm{P}_{\mathrm{n}}$ of the elevated $\mathrm{CO}_{2}$-grown $\mathrm{WT}$ was $10.4 \pm 1.1$ and $19.7 \pm 1.3 \mu \mathrm{mol} \mathrm{m}^{-2} \mathrm{~s}^{-1}$ when measured at 35 and $70 \mathrm{PaCO}_{2}$, respectively. Rates of $P_{n}$ Of the ambient $\mathrm{CO}_{2}$-grown MUT were $10.5 \pm 0.7$ and $16.4 \pm 1.1 \mu \mathrm{mol} \mathrm{m}^{-2} \mathrm{~s}^{-1}$ at 35 and $70 \mathrm{~Pa} \mathrm{CO}_{2}$, respectively. Rates of $\mathrm{P}_{\mathrm{n}}$ measured at 35 and $70 \mathrm{~Pa} \mathrm{CO}_{2}$ were unaffected by $21 \mathrm{~d}$ of $\mathrm{CO}_{2}$ enrichment $(P>0.05)$, when averaged over both genotypes. However, a significant $\mathrm{CO}_{2}$ by genotype interaction $(P<0.05)$ was detected for $P_{n}$ rates measured at $35 \mathrm{PaCO}_{2}$. This indicated that $\mathrm{P}_{n}$ rates of the two genotypes responded differently to $\mathrm{CO}_{2}$ 
Table 2. Effects of $\mathrm{CO}_{2}$ enrichment on net photosynthesis and Rubisco activity of wild type (WT) and starchless mutant (MUT) NS458 of Nicotiana sylvestris. Values are means \pm se for $\mathrm{n}=8$.

\begin{tabular}{|c|c|c|c|c|c|c|c|}
\hline \multirow[t]{2}{*}{ Sample } & \multicolumn{2}{|c|}{ Photosynthetic Rate } & \multirow[b]{2}{*}{$\Delta$} & \multicolumn{2}{|c|}{ Rubisco Activity } & \multirow[b]{2}{*}{$\Delta$} & \multirow{2}{*}{$\begin{array}{c}\text { Percent } \\
\text { Activ. }\end{array}$} \\
\hline & $35 \mathrm{~Pa} \mathrm{CO}_{2}$ & $70 \mathrm{~Pa} \mathrm{CO}_{2}$ & & Initial & Total & & \\
\hline \multicolumn{8}{|c|}{$\mu \mathrm{mol} \mathrm{m}{ }^{-2} \mathrm{~s}^{-1}$} \\
\hline WT-ambient & $13.7 \pm 0.4$ & $22.6 \pm 0.8$ & 8.9 & $40.4 \pm 6.8$ & $50.1 \pm 5.3$ & 9.7 & 81 \\
\hline WT-elevated & $10.4 \pm 1.1$ & $19.7 \pm 1.3$ & 9.3 & $36.0 \pm 6.3$ & $47.6 \pm 7.4$ & 11.6 & 76 \\
\hline MUT-ambient & $10.5 \pm 0.7$ & $16.4 \pm 1.1$ & 5.9 & $26.0 \pm 3.4$ & $44.0 \pm 2.4$ & 18.0 & 59 \\
\hline MUT-elevated & $11.0 \pm 0.5$ & $16.9 \pm 0.6$ & 5.9 & $26.5 \pm 3.3$ & $37.5 \pm 2.6$ & 11.0 & 71 \\
\hline
\end{tabular}

enrichment. Averaged over $\mathrm{CO}_{2}$ treatments, $\mathrm{P}_{\mathrm{n}}$ of the MUT and WT also differed $(P<0.001)$ when rates were measured at $70 \mathrm{PaCO}_{2}$. The ratio of $\mathrm{P}_{n}$ measured at 35 and $70 \mathrm{~Pa} \mathrm{CO}_{2}$, which is an estimate of photosynthetic enhancement, was 1.6 for both ambient $\mathrm{CO}_{2}$-grown WT and MUT plants, whereas $\mathrm{P}_{\mathrm{n}}$ ratios for elevated $\mathrm{CO}_{2}$-grown plants were $1.9(\mathrm{WT})$ and 1.5 (MUT), respectively.

In the current study, Rubisco activity was determined before and after in vitro activation with $\mathrm{CO}_{2}$ and $\mathrm{Mg}^{2+}$. In contrast to similar experiments performed with $\mathcal{N}$. tabacum, ${ }^{(14,13)}$ Rubisco was less than fully activated in the WT and MUT leaf samples of the current study. Averaged over $\mathrm{CO}_{2}$ treatments, initial activity was $78 \%$ and $65 \%$ of total Rubisco activity in WT and MUT samples $(P<0.05)$, respectively. Doubling the elevated $\mathrm{CO}_{2}$ concentration for $21 \mathrm{~d}$ had no affect on either initial or total Rubisco activity, when results for the WT and MUT were combined for analysis. Total Rubisco activities of WT and MUT samples were not significantly different $(P>0.05)$, possibly because plant to plant variability was high. However, when averaged over both $\mathrm{CO}_{2}$ treatments, initial Rubisco activity of MUT samples was $32 \%$ less than that of the WT $(P<0.05)$.

\section{Leaf metabolites}

Effects of $\mathrm{CO}_{2}$ enrichment on various metabolises in WT and MUT leaf samples are presented in Table 3. None of the principal storage carbohydrates in this study, i.e., starch, sucrose, glucose or fructose, was significantly different $(P>0.05)$ when ambient and elevated $\mathrm{CO}_{2}$ treatments were compared. In agreement with published findings, ${ }^{\left({ }^{(}\right)}$ leaf starch levels were about 10 fold greater in the
WT than in the MUT. Present results confirmed that glucose and fructose concentrations were greater $(P<0.05)$ in the MUT than in the WT.

Levels of 3-PGA were $25 \%$ to $35 \%$ greater and whole leaf Ru1,5bisP concentrations were unaffected $(P>0.05)$ by doubling the ambient $\mathrm{CO}_{2}$ partial pressure from 35 to $70 \mathrm{~Pa}$. Levels of $\mathrm{Rul}, 5 \mathrm{bisP}$ were 2-4 fold greater in the MUT than in the WT $(P<0.05)$. For ambient $\mathrm{CO}_{2}$-grown plants, the 3 PGA/Rul,5bisP ratios were 10.2 and 5.1 for WT and MUT lines, respectively. In comparison, the 3PGA/Rul,5bisP ratio was 18.1 and 4.2 for elevated $\mathrm{CO}_{2}$-grown WT and MUT lines, respectively.

\section{DISCUSSION}

We have examined feedback control mechanisms that limit $\mathrm{P}_{\mathrm{n}}$ by altering Rubisco activity. Our hypothesis, that a down regulation of Rubisco activity would be observed in the starchless MUT grown at ambient and twice ambient $\mathrm{CO}_{2}$ partial pressures, was supported. Evidence of decreased Rubisco activity was obtained from gas exchange analysis, Rubisco enzyme and protein assays and metabolite measurements using a starchless tobacco MUT.

According to theory, ${ }^{(1,9)}$ three biochemical processes can impose a limitation on the in vivo rate of $\mathrm{CO}_{2}$ fixation. Inhibition of $\mathrm{P}_{\mathrm{n}}$ measured at low internal $\mathrm{CO}_{2}$ concentrations indicates a Rubisco activity limitation. An inhibition of $P_{n}$ at above ambient $\mathrm{CO}_{2}$ suggests that the $\mathrm{CO}_{2}$ fixation rate was limited by rates of $\mathrm{Ru} 1,5 \mathrm{bis} \mathrm{P}$ regeneration. An end product synthesis limitation occurs when rates of starch and sucrose synthesis are low and insufficient inorganic phosphate $(\mathrm{Pi})$ is available to sup- 
Table 3. Effects of $\mathrm{CO}_{2}$ enrichment on leaf metabolite concentrations in WT and MUT lines of Nicotiana sylvestris. Values are means \pm se for $\mathrm{n}=8$.

\begin{tabular}{|c|c|c|c|c|c|c|}
\hline Sample & Starch & Sucrose & Glucose & Fructose & Rul,5bisP & 3-PGA \\
\hline & \multicolumn{4}{|c|}{$\mathrm{mmol} \mathrm{m}^{-2}$} & \multicolumn{2}{|c|}{$\mu \mathrm{mol} \mathrm{m}^{-2}$} \\
\hline WT-ambient & $27.2 \pm 3.3$ & $8.6 \pm 1.6$ & $4.9 \pm 0.6$ & $1.6 \pm 0.3$ & $21 \pm 2$ & $214 \pm 32$ \\
\hline WT-elevated & $31.0 \pm 3.2$ & $8.6 \pm 0.8$ & $6.0 \pm 0.7$ & $1.6 \pm 0.2$ & $15 \pm 1$ & $271 \pm 16$ \\
\hline MUT-ambient & $2.9 \pm 0.1$ & $9.0 \pm 1.9$ & $7.6 \pm 0.5$ & $2.5 \pm 0.3$ & $40 \pm 6$ & $202 \pm 23$ \\
\hline MUT-elevated & $3.7 \pm 0.3$ & $9.2 \pm 1.7$ & $9.1 \pm 0.7$ & $2.6 \pm 0.3$ & $62 \pm 6$ & $263 \pm 27$ \\
\hline
\end{tabular}

port photophosphorylation. Evidence of an end product synthesis limitation is derived from a lack of stimulation of $\mathrm{P}_{\mathrm{n}}$ when the $\mathrm{O}_{2}$ concentration is decreased or the $\mathrm{CO}_{2}$ concentration is increased. ${ }^{(4,5)}$

In the current study, rates of $P_{n}$ were measured at the reciprocal $\mathrm{CO}_{2}$ partial pressures used for plant growth. Averaged over genotypes, rates of $P_{n}$ measured at 35 and at $70 \mathrm{PaCO}_{2}$ were unaffected by either long-term growth $\mathrm{CO}_{2}$ treatment. However, a $\mathrm{CO}_{2}$ by genotype interaction was detected for measurements of $\mathrm{P}_{\mathrm{n}}$ performed at $35 \mathrm{~Pa}$ $\mathrm{CO}_{2}$. This indicated that $\mathrm{P}_{\mathrm{n}}$ rates of the $\mathrm{WT}$ and MUT measured at $35 \mathrm{~Pa} \mathrm{CO}_{2}$ responded differently to $\mathrm{CO}_{2}$ enrichment. We propose that the differing effects of $\mathrm{CO}_{2}$ enrichment on rates of $\mathrm{P}_{n}$ of the WT and MUT measured at $35 \mathrm{~Pa} \mathrm{CO}_{2}$ arose because of altered Rubisco activity in the starchless MUT. There was considerable evidence suggesting that Rubisco activity was modified in the MUT. First, Rubisco protein concentrations were lower in the MUT than in the WT. Also, Rubisco protein levels in the WT and MUT were decreased in response to $\mathrm{CO}_{2}$ enrichment. Reduced Rubisco concentrations in response to $\mathrm{CO}_{2}$ enrichment have previously been observed in rice, ${ }^{(17)}$ tomato ${ }^{(18,19)}$ and $\mathcal{N}$. tabacum. ${ }^{(14,13)}$ Second, activation of Rubisco was decreased in the MUT compared to the WT. Rubisco was only partially activated in $\mathcal{N}$. sylvestris, whereas Rubisco was fully activated in both elevated and ambient $\mathrm{CO}_{2}$-grown $\mathcal{N}$. tabacum at a similar PPFD ${ }^{(13)}$ Third, Ru1,5bisP levels were up to 4-fold greater in the MUT than in the WT. The above findings collectively support the suggestion that decreased rates of $P_{n}$ of the MUT measured at $35 \mathrm{~Pa} \mathrm{CO}_{2}$ relative to the WT were affected by decreased Rubisco activity.

In agreement with published findings using shortterm elevated $\mathrm{CO}_{2}$ treatments, ${ }^{(10)}$ rates of $\mathrm{P}_{\mathrm{n}}$ of ambient and elevated $\mathrm{CO}_{2}$-grown WT and MUT NS 458 differed at $70 \mathrm{~Pa} \mathrm{CO}_{2}$. Hanson ${ }^{(10)}$ concluded that $P_{n}$ rates of starchless MUT NS 514 measured at $70 \mathrm{~Pa} \mathrm{CO}_{2}$ were inhibited by rates of end product synthesis. Butz and Sharkey ${ }^{(20)}$ reported that Rubisco was deactivated and Rul,5bisP accumulated in the chloroplast when $\mathrm{P}_{\mathrm{n}}$ was limited by rates of end product synthesis. Both deactivation of Rubisco and elevated Ru $\mathrm{R}, 5$ bisP levels were observed in the ambient and elevated $\mathrm{CO}_{2}$-grown starchless MUT relative to the WT. However, rates of $P_{n}$ by the MUT increased $56 \%$ when the measurement $\mathrm{CO}_{2}$ partial pressure was doubled. Therefore, it was unlikely that rates of $P_{n}$ of the MUT measured at $35 \mathrm{~Pa} \mathrm{CO}_{2}$ were limited by rates of end product synthesis. An accumulation of Rul,5bisP and deactivation of Rubisco in the starchless MUT may represent a biochemical adjustment to a defective starch pathway. Sharkey and Vanderveer ${ }^{(5)}$ have argued that a buildup of Rul,5bisP in the chloroplast should sequester inorganic phosphate, a condition that would stimulate starch biosynthesis in WT plants.

Photosynthetic acclamation is a change of $P_{n}$ in response to long term (days to weeks) growth in elevated $\mathrm{CO}_{2}$ and depending upon species can be either positive or negative. In prior studies using $\mathcal{N}$. tabacum, ${ }^{(16,14,13)}$ plant dry weight, SLW, and leaf starch increased, and photosynthetic capacity and Rubisco activity decreased in elevated compared to ambient $\mathrm{CO}_{2}$-grown plants. Acclimation of $\mathrm{P}_{\mathrm{n}}$ in $\mathcal{N}$. tabacum was strongly negative when measured at 35 and $70 \mathrm{~Pa} \mathrm{CO}_{2}$ both at moderate and at low PPFD. In contrast to the above, evidence of photosynthetic acclimation in elevated $\mathrm{CO}_{2}$ grown $\mathcal{N}$. sylvestris was limited. Shoot biomass of WT and MUT lines of $\mathcal{N}$. syluestris did not differ between the ambient and elevated $\mathrm{CO}_{2}$ treatments. Starch and sucrose con- 
centrations of the WT and MUT also were unaffected by the elevated $\mathrm{CO}_{2}$ treatment. However, SLW was about $20 \%$ greater in elevated than in ambient $\mathrm{CO}_{2}$-grown plants, indicating that SLW was less variable on a per plant basis than was either dry weight or leaf area. The differing acclimation responses of $\mathcal{N}$. tabacum and $\mathcal{N}$. sylvestris to $\mathrm{CO}_{2}$ enrichment can not be explained at this time.

In summary, rates of $P_{n}$ of ambient and elevated $\mathrm{CO}_{2}$-grown WT and MUT plants differed when measured at $35 \mathrm{~Pa} \mathrm{CO}_{2}$. The observation that Rul,5bisP was increased, percent Rubisco activation was decreased and Rubisco protein levels were decreased in the MUT relative to the WT was consistent with the suggestion that $P_{n}$ in the absence of starch synthesis was limited by Rubisco activity. A Rubisco activity limitation and an end product synthesis limitation of $P_{n}$ in the MUT were detected for $\mathrm{CO}_{2}$ fixation rates measured at $35 \mathrm{~Pa}$ and at $70 \mathrm{~Pa} \mathrm{CO}_{2}$, respectively. Total biomass, shoot growth and carbohydrate accumulation in $\mathcal{N}$. sylvestris were virtually unaffected by $25 \mathrm{~d}$ exposure to $70 \mathrm{~Pa} \mathrm{CO}_{2}$ air. There were fewer effects of $\mathrm{CO}_{2}$ enrichment on $\mathcal{N}$. sylvestris than in prior studies using N. tabacum. ${ }^{(14,13)}$

Acknowledgements - The authors would like to thank D. Lee for measuring photosynthesis and J. Bunce and $\mathrm{M}$. Holden for helpful comments on the manuscript.

Mention of a trademark, proprietary product or vendor neither implies an endorsement nor constitutes a warranty of the product by the U. S. Department of Agriculture.

\section{REFERENCES}

1. Sharkey T.D. (1985) Photosynthesis in intact leaves of $\mathrm{C}_{3}$ plants: physics, physiology and rate limitations. Bot. Rev. 51, 53-106.

2. Stitt M. (1991) Rising $\mathrm{CO}_{2}$ levels and their potential significance for carbon flow in photosynthetic cells. Plant Cell Environ. 14, 741-762.

3. Herold A. (1980) Regulation of photosynthesis by sink activity: the missing link. New Phytol. 86, 131144.

4. Sharkey T.D. (1985) $\mathrm{O}_{2}$-insensitive photosynthesis in $\mathrm{C}_{3}$ plants: Its occurrence and a possible explanation. Plant Physiol. 78, 71-75.

5. Sharkey T.D., Vandeveer P.J. (1989) Stromal phos- phate concentration is low during feedback limited photosynthesis. Plant Physiol. 91, 679-684.

6. Walker D.A. and Sivak M. (1985) Can phosphate limit photosynthetic carbon assimilation in viwo? Physiol. Vég. 23, 829-841.

7. Caspar T., Huber S.C. and Somerville C. (1985) Alterations in growth, photosynthesis, and respiration in a starchless mutant of Arabidopsis thaliana (L.) deficient in chloroplast phosphoglucomutase activity. Plant Physiol. 79, 11-17.

8. Hanson K.R. and McHale N.A. (1988) A starchless mutant of Nicotiana sylvestris containing a modified plastid phosphoglucomutase. Plant Physiol. 88, 838844.

9. Smith A.M., Neuhaus H.E. and Stitt M. (1990) The impact of decreased activity of starch branching enzyme on photosynthetic starch synthesis in leaves of wrinkled pea seeds. Planta 181, 310-315.

10. Hanson K.R. (1990) Steady-state and oscillating photosynthesis by a starchless mutant of Nicotiana sylvestris. Plant Physiol. 93, 1212-1218.

11. Webber A.N., Nie G.-Y. and Long S.P. (1994) Acclimation of photosynthetic proteins to rising atmospheric $\mathrm{CO}_{2}$. Photosyn. Res. 39, 413-425.

12. Peet M.M., Huber S.C. and Patterson D.T. (1986) Acclimation to high $\mathrm{CO}_{2}$ in monoecious cucumbers. II. Carbon exchange rates, enzyme activities and starch and nutrient concentrations. Plant Physiol. 80, 63-67.

13. Sicher R.C., Kremer D.F. and Rodermel S.R. (1994) Photosynthetic acclamation to elevated $\mathrm{CO}_{2}$ occurs in transformed tobacco with decreased ribulose-1,5bisphosphate carboxylase/oxygenase content. Plant Physiol. 104, 409-415.

14. Sicher R.C. and Kremer D.F. (1994) Responses of Nicotiana tabacum (L.) to $\mathrm{CO}_{2}$ enrichment at low-photon flux density. Physiol. Plant. 92, 383-388.

15. Bunce J.A. (1992) Light, temperature and nutrients as factors in photosynthetic adjustment to an elevated concentration of carbon dioxide. Physiol. Plant. 86, 173-179.

16. Raper C.D.Jr. and Peedin G.F. (1978) Photosynthetic rate during steady-state growth as influenced by carbon dioxide concentration. Bot. Gaz. 139, 147-149.

17. Rowland-Bamford A.J., Baker J.T., Allen L.H.Jr. and Bowes G. (1991) Acclimation of rice to changing atmospheric carbon dioxide concentration. Plant Cell Environ. 14, 577-583.

18. Besford R.T., Ludwig L.J. and Withers A.C. (1990) The greenhouse effect: Photosynthesis and ribulose 1,5-bisphosphate carboxylase protein. 7. Exp. Bot. 41, 925-931.

19. Yelle S., Besson R.C., Trudel M.J. and Gosselin A. (1989) Acclimation of two tomato species to high 
atmospheric $\mathrm{CO}_{2}$. Ribulose 1,5-bisphosphate carboxylase/oxygenase and phosphoenol pyruvate carboxylase. Plant Physiol. 90, 1473-1477.

20. Butz N.D. and Sharkey T.D. (1989) Activity ratios of ribulose 1,5-bisphosphate carboxylase accurately reflect carbamylation ratios. Plant Physiol. 89, 735739.
21. Sicher R.C., Kremer D.F. and Harris W.G. (1986) Control of photosynthetic sucrose synthesis in barley primary leaves. Role of fructose 2,6-bisphosphate. Plant Physiol. 37, 716-721.

22. Sicher R.C. and Kremer D.F. (1988) Effects of phosphate deficiency on assimilate partitioning in barley seedlings. Plant Sci. 57, 9-17. 